\title{
Electrochemical Hydrogen Oxidation on Pt(100): a Combined Direct Molecular Dynamics/Density Functional Theory Study
}

\author{
Juan A. Santana ${ }^{1,3}$ • José J. Saavedra-Arias ${ }^{1,2}$ • Yasuyuki Ishikawa ${ }^{1}$
}

Published online: 9 August 2015

(C) Springer Science+Business Media New York 2015

\begin{abstract}
We have studied the hydrogen oxidation reaction on various catalytic sites at the water/Pt(100) interface with first-principles direct molecular dynamics and minimum energy pathway calculations. The calculations indicate that the mechanism for electro-oxidation of $\mathrm{H}_{2}$ on terrace sites of the $\operatorname{Pt}(100)$ surface depends on the concentration of inactive adsorbed hydrogen on the electrode surface. Near the reversible potential, the electro-oxidation follows the Tafel-Volmer homolytic cleavage of $\mathrm{H}_{2}$ at low coverage of adsorbed hydrogen. If the surface is covered with ca. 1 monolayer of hydrogen, however, the oxidation proceeds by the Heyrovsky-Volmer mechanism. We found good agreement between measured and predicted Tafel plots, indicating that hydrogen oxidation/reduction reaction on $\operatorname{Pt}(100)$ takes place via the Heyrovsky-Volmer mechanism under ca. 1 monolayer coverage of inactive adsorbed hydrogen.
\end{abstract}

Keywords Electrocatalysis · Surface catalysis $\cdot$ Fuel cells . Proton-coupled electron-transfer .

Heyrovsky- and Tafel-Volmer mechanisms

Juan A. Santana

juan.santana6@upr.edu

1 Department of Chemistry, University of Puerto Rico at Rio Piedras, P.O. Box 23346, San Juan, PR 00931, USA

2 Department of Physics, Universidad Nacional, Heredia 40101, Costa Rica

3 Present address: Department of Chemistry, University of Puerto Rico at Cayey, P. O. Box 372230, Cayey, PR 00737-2230, USA

\section{Introduction}

The hydrogen evolution reaction (HER) and hydrogen oxidation reaction (HOR) on $\mathrm{Pt}$ electrodes are among the most studied electrochemical processes because of their practical importance [1]. The mechanistic details of the electrocatalytic HOR on low-index Pt $(h k l)$ single crystals in acid solution has received renewed interest in the recent years because of the potential of hydrogen-based fuel cells [2], where the HOR occurs, for instance, at the anode of the proton-exchange membrane fuel cells.

It is generally accepted that HOR on low-index $\mathrm{Pt}(h k l)$ single crystals involve the following elementary steps: [3]

$$
\begin{aligned}
& \mathrm{H}_{2} \rightarrow \mathrm{H}_{\mathrm{ads}}+\mathrm{H}_{\mathrm{ads}} \quad \text { (Tafel) }, \\
& \mathrm{H}_{2} \rightarrow \mathrm{H}_{\mathrm{ads}}+\mathrm{H}^{+}+\mathrm{e}^{-} \quad \text { (Heyrovsky), } \\
& \mathrm{H}_{\mathrm{ads}} \rightarrow \mathrm{H}^{+}+\mathrm{e}^{-} \quad \text { (Volmer). }
\end{aligned}
$$

The overall HOR, $\mathrm{H}_{2} \rightarrow 2 \mathrm{H}^{+}+2 e^{-}$, involves $\mathrm{H}_{2}$ dissociation either by the Tafel or the Heyrovsky reaction step, followed by the oxidation of $\mathrm{H}_{\mathrm{ads}}$ via the Volmer process.

Despite these apparently simple mechanisms proposed for the HER/HOR on low-index Pt $(h k l)$ single crystals, there have been controversies in the literature concerning the detailed reaction mechanism, the nature of the hydrogen intermediate involved, and the effect of the microstructure of the Pt surface on the electrochemical reactions. In early studies, the inability to accurately identify the structure of adsorbates led to the proposal of numerous mechanistic pathways for the electrocatalytic HOR/HER [1]. Several studies reported that the electrochemical HOR/HER was insensitive to the $\mathrm{Pt}(h k l)$ structure; see Ref. [4] and references therein. Later works, however, found that the kinetics of the HER/HOR on $\mathrm{Pt}(h k l)$ in alkaline [5] and acid [6] solutions vary with crystal faces. In 
acid electrolytes, for instance, a study [6] of the hydrogen electrochemistry found that each crystal face possesses a unique temperature-dependent Tafel slope for the HOR and the activation energies $\left(E_{a}\right)$ for the HER/HOR decreases in the sequence $(111)>(100)>(110)$. These differences in $E_{a}$ with the crystal faces were attributed to structure-sensitive heats of adsorption of the active intermediate $\mathrm{H}_{\mathrm{ads}}$ [6], whose physical state is still unclear.

Surface spectroscopic techniques have provided the most atomic scale detailed look at electrocatalytic reactions on $\mathrm{Pt}$ polycrystalline [3, 7-10] and low-index single crystal surfaces [3, 7, 11, 12]. In in situ IR spectroscopy studies [3], a Pt-H stretching vibration at $2090 \mathrm{~cm}^{-1}$ was identified on Pt polycrystalline and (111) single crystal electrodes at potentials below $110 \mathrm{mV}$ vs. the reversible hydrogen electrode (RHE). The electrochemical hydrogen adsorption on $\operatorname{Pt}(100), \operatorname{Pt}(1111)$, $\operatorname{Pt}(110)$, and $\mathrm{Pt}(111)$ electrode surfaces was later studied [11] using in situ IR reflection absorption spectroscopy, and it was shown that the terminal hydrogen adsorption is sensitive to the surface crystallographic orientation. The IR bands of the adsorbed hydrogen on $\operatorname{Pt}(100), \operatorname{Pt}(1111)$, and $\operatorname{Pt}(110)$ were observed at $1990-2080 \mathrm{~cm}^{-1}$ at potentials more negative than $+0.25 \mathrm{~V}$ vs. RHE. A further study [7] with the infrared-visible sum frequency generation (SFG) technique showed the vibrational signature of terminal hydrogen on low-index $\mathrm{Pt}(h k l)$ at $1800-2020 \mathrm{~cm}^{-1}$. In a more recent work [12], hydrogen adsorption on $\operatorname{Pt}(h k l)$, and $\operatorname{Pt}(211)$, and $\operatorname{Pt}(311)$ was studied using in situ IR reflection absorption spectroscopy. In that work [12], the band around $2080 \mathrm{~cm}^{-1}$ was observed only for hydrogen adsorbed on Pt(110) and stepped Pt surfaces at potentials near $0 \mathrm{~V}$ vs. RHE.

Computational modeling, particularly those based on density functional theory (DFT), have been increasingly employed to study electrochemical reactions [13-15] with different schemes and approximations [16-27] to simulate electrochemical conditions. The mechanistic pathways of the HER/HOR on Pt electrodes have been explored with DFT and model systems of a Pt atom with a solvated $\mathrm{H}^{+}$[16], micro-solvated Pt clusters [21], and slab models of the electrolyte/Pt interface [22-26].

In previous studies [21,28], we conducted first-principles direct molecular dynamics (MD) study of the HOR at the water/Pt(111) interface. Our calculations showed that the HOR on this surface proceeds via the Heyrovsky-Volmer mechanism with $\mathrm{H}^{+}$and inert adsorbed bridging hydrogen $\left(\mathrm{H}_{\mathrm{b}}\right)$ as reaction products. $\mathrm{H}_{\mathrm{b}}$ on $\operatorname{Pt}(111)$ was identified as the underpotential-deposited hydrogen, the so-called UPD H $[21,28]$. On the other hand, a following study [29] revealed that the HOR on the $\operatorname{Pt}(110)$ follows the Tafel-Volmer mechanism with hydrogen adsorbed at the on-top site $\left(\mathrm{H}_{\mathrm{o}}\right)$ as the intermediate species. The Pt-H stretching frequency $2083 \mathrm{~cm}^{-1}$ was predicted for $\mathrm{H}_{\mathrm{o}}$ on $\operatorname{Pt}(110)$ near the reversible potential, in agreement with the IR band at $2080 \mathrm{~cm}^{-1}[11,12]$.
In the present study, the mechanistic details of the HOR on $\mathrm{Pt}(100)$ are examined in detail using direct MD simulation and DFT methods. We address the adsorbed UPD states of hydrogen and their possible involvement in the electrocatalytic processes. The mechanisms for the formation of UPD $\mathrm{H}$ on $\mathrm{Pt}(100)$ at ca. 1 monolayer (ML) coverage are still not well understood, and thus, a detailed theoretical study is expected to complement previous experimental [6] and theoretical studies $[16,26] . \mathrm{E}_{\mathrm{a}}$ for the oxidation of hydrogen on $\operatorname{Pt}(100)$ is calculated and compared with those on $\operatorname{Pt}(110)$ and $\operatorname{Pt}(111)$, and experiment. The study will help to approach an understanding of the relationship between the electrocatalytic behavior of the anodic HOR and the adsorbed UPD state of hydrogen at low- and high-coverage states at the water/ $\operatorname{Pt}(100)$ interface.

\section{Computational Details}

To study the electrochemical hydrogen oxidation at the water/ $\operatorname{Pt}(100)$ interface, we employed a cluster model. The oxidation mechanism was established performing direct MD based on DFT. The direct MD results were then verified with minimum energy pathway (MEP) calculations. In this section, we describe the DFT calculations, cluster models, electrode potential modeling, and the MEP and direct MD calculations.

DFT calculations were carried out with the DMol [3] software package [30]. We used double numerical quality basis sets with polarization functions (DNP) [30] to expand the Kohn-Sham orbitals and the Perdew-Burke-Ernzerhof (PBE) [31] exchange-correlation functional. DNP basis sets minimize superposition errors and correctly describe molecular polarizabilities [30]. For geometry relaxation, the core potentials were represented with DFT semi-local pseudo-potentials (DSPP). Final total energies were then evaluated with an allelectron scalar relativistic algorithm [30] to obtain accurate energies. The combination of PBE and the all-electron scalar relativistic algorithm implemented in Dmol [3] has been shown to be accurate for binding and reaction energy of hydrogen on Pt surfaces [21, 29]. The technique [30] of fractional occupation numbers was used applying a Fermi smearing of $0.1 \mathrm{eV}$ to accelerate the convergence of the Self-ConsistentField (SCF) procedure.

Metal clusters with 37 and $39 \mathrm{Pt}$ atoms (Fig. 1) were used to simulate $\mathrm{Pt}(100)$ with terrace and (111) step sites, respectively. Cluster thickness effects on the energetics of hydrogen on $\mathrm{Pt}(100)$ are expected to be below $1 \mathrm{kcal} / \mathrm{mol}[21,29]$. The binding energy of $\mathrm{H}_{\mathrm{o}}$ on clean $\mathrm{Pt}(100)$ and at water/Pt(100) interface calculated with our models are 64 and $63 \mathrm{kcal} / \mathrm{mol}$, respectively. For $\mathrm{H}_{\mathrm{b}}$ on clean $\mathrm{Pt}(100)$ and at water $/ \mathrm{Pt}(100)$ interface, calculations with our models yield 67 and $68 \mathrm{kcal} /$ mol, respectively. These results are in good agreement with the measured values for hydrogen on $\mathrm{Pt}(100)$ under high 

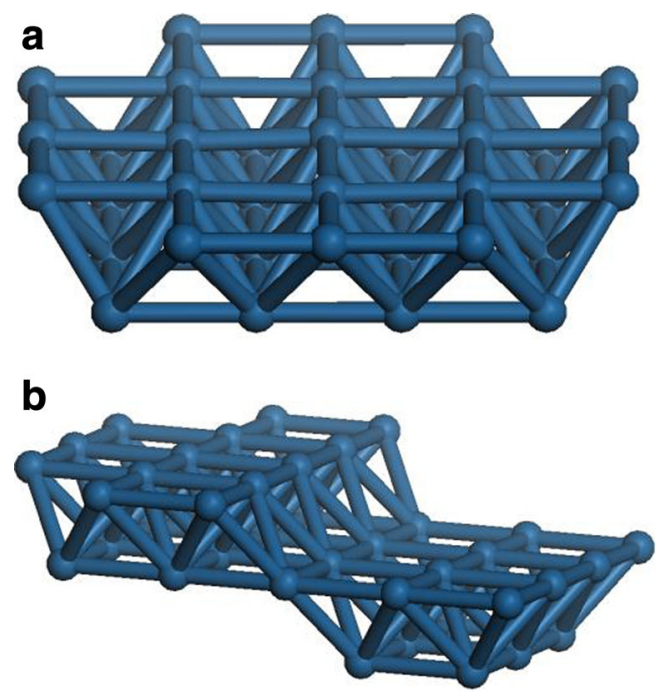

Fig. 1 Cluster models employed to simulate a $\mathrm{Pt}_{37}(100)$ terrace sites and b $\mathrm{Pt}_{39}(100)$ with (111) step sites

vacuum [32] and electrochemical conditions [33, 34], i.e., 63 and $64-65 \mathrm{kcal} / \mathrm{mol}$, respectively. A similar agreement was found for hydrogen $\operatorname{Pt}(111)$, where our calculations with the two-layer cluster model yielded [21] a hydrogen binding energy of $56 \mathrm{kcal} / \mathrm{mol}$, in close agreement with the experimental value [35] 57-60 kcal/mol. Moreover, the binding energy of hydrogen on Pt(111) evaluated with our cluster models agrees with calculations from extended surface models [21].

The water/Pt(100) interface was created by adding up to 18 water molecules on one side of the cluster models. Geometry optimizations of the water $/ \mathrm{Pt}(100)$ systems were performed by allowing all solvent water molecules and the top layer of the $\mathrm{Pt}$ clusters to relax freely until residual forces were below $0.03 \mathrm{eV} / \AA$. The bottom layer of the Pt clusters was held fixed to the experimental position of bulk Pt, $a=3.92 \AA$.

As in our previous works [21, 29], the effective electrode potential in the Pt clusters was controlled adding/ removing a given number of electrons (charge $q$ ) to/from the water/ $\operatorname{Pt}(100)$ systems. In our method, the electrode potential $U(q)$ is established by a linear interpolation of two characteristic potentials: (i) the hydrogen reversible potential and (ii) the water/ $\operatorname{Pt}(100)$ ionization potential (IP) relative to the thermodynamic work function [36] of the standard hydrogen electrode. By definition, gaseous $1 / 2 \mathrm{H}_{2}$ is in equilibrium with $\left(\mathrm{H}_{3} \mathrm{O}^{+}+e^{-}\right)$at water/ $\mathrm{Pt}(100)$ interface at the reversible potential. Therefore, in our method, the charge $q$ where the energy of gaseous $1 / 2 \mathrm{H}_{2}$, solvated $\mathrm{H}_{3} \mathrm{O}^{+}$, and $e^{-}$in the metal electrode are equal corresponds to the hydrogen reversible potential. At this potential, $\mathrm{E}_{\mathrm{a}}$ of the Volmer step in the hydrogen oxidation $\left(\mathrm{H}_{\mathrm{ads}} \rightarrow \mathrm{H}_{3} \mathrm{O}^{+}+e^{-}\right)$and hydrogen evolution $\left(\mathrm{H}_{3} \mathrm{O}^{+}+e^{-} \rightarrow \mathrm{H}_{\mathrm{ads}}\right)$ reactions is also equal. Similar to our calculations with cluster models of the water/Pt(111) [21] and water/Pt(110) [29] interfaces, the reversible potential for the water/Pt(100) interfaces is near $q=-2$ (Figs. 6 and 9) and the IP relative to RHE is ca. $+0.2 \mathrm{~V}$ for the water/ $\operatorname{Pt}(100)$ interface.

Minimum energy pathways were determined approximately with an elastic band method. The points in the band were generated gradually connecting reactants and products. Each point is partially optimized minimizing forces and energy. The approximate transition state structures were checked by a normal mode analysis to exhibit a single imaginary frequency.

The direct MD method employed in the present work has been developed and implemented in our group [21]. The method is a quantum-classical simulation where at each time step the energy gradient in the classical evolution of the atomic nuclei is evaluated with an electronic structure approach, e.g., DFT. The hydrogen oxidation is a proton-coupled electron-transfer reaction and non-adiabatic quantum effects are non-negligible [37]. We, however, treated all nuclei classically. Instead of fitting the potential surface to an analytic form beforehand, we generated it "on the fly." In this way, we avoid the complications of constructing an accurate surface. Generating the surface on the fly restricts the dynamics of reactive systems from being examined in as much detail as they can be on a fitted surface. However, the direct MD is a more practical approach for large complex systems.

The classical equation of motion in our MD was integrated using the Verlet algorithm with a time step of 0.5 femtoseconds (fs). DMol [3] was employed to evaluate the energies and gradients with DFT calculations. All water molecules and the $\mathrm{H}_{2}$ molecule began each direct MD trajectory with vibrational but no rotational energy. Zero-point vibrational energy was not given to the Pt cluster. During the direct MD simulation, the water molecules, hydrogen atoms and the top layer of the Pt clusters were allowed to move freely. The bottom layer of the Pt clusters was held fixed to the experimental position of bulk Pt. A number of trajectories with initial $\mathrm{H}_{2}-\mathrm{Pt}(100)$ separations ranging from 2.5 to $3.5 \AA$ were chosen and each one lead to dissociative $\mathrm{H}_{2}$. The 18 water molecules allowed the $\mathrm{H}^{+}$oxidation product to fluctuate between a variety of structures, such as $\mathrm{H}_{5} \mathrm{O}_{2}{ }^{+}$(Zundel ion) and $\mathrm{H}_{9} \mathrm{O}_{4}{ }^{+}$[38].

\section{Results and Discussion}

The main features of the voltammogram of well-ordered $\mathrm{Pt}(100)$ in acid solution, e.g., $0.05 \mathrm{M} \mathrm{H}_{2} \mathrm{SO}_{4}$ [6], are two delineated peaks at ca. +0.25 and $+0.4 \mathrm{~V}$ vs. RHE. The + 0.25 and $+0.4 \mathrm{~V}$ peaks have been associated with the coupling of hydrogen adsorption/desorption with the anion desorption/ adsorption on the $n(100) \times(111)$ step sites and (100) terrace sites, respectively [6]. In the present work, we are mainly interested in the HOR at potentials below $+0.2 \mathrm{~V}$ vs. RHE. Therefore, the effects of anion adsorption have not been considered. We focused our study on the (100) terrace sites, 
although the $n(100) \times(111)$ step site was also studied to a lesser extent.

The HOR on Pt electrodes is very sensitive to the electrode potential $[16,21,28,29]$. Moreover, at low overpotential, the Pt surface is covered with spectator-adsorbed hydrogen, and the HOR is expected to take place under high coverage of adsorbed hydrogen $[39,40]$. We studied the effect of hydrogen coverage and electrode potential on the HOR on $\mathrm{Pt}(100)$, performing two series of calculations: (i) HOR at low coverage of adsorbed hydrogen at ca. 0.0 and $+0.2 \mathrm{~V}$ vs. RHE and (ii) HOR at ca. $1 \mathrm{ML}$ coverage of adsorbed hydrogen at ca. $0.0 \mathrm{~V}$ vs. RHE.

The high coverage of hydrogen under electrochemical conditions have been recently studied on $\operatorname{Pt}(111)[26,28,34]$, $\operatorname{Pt}(110)$ [26, 29, 34], and $\operatorname{Pt}(100)$ [26, 34]. The state of adsorbed hydrogen at high coverage, i.e., the UPD state of hydrogen, on $\mathrm{Pt}(111)$ and $\mathrm{Pt}(110)$, is still controversial as it has been identified by different calculations as hydrogen on bridge [21, 28], and hollow site [20, 24, 26] on Pt(111) and hydrogen on-top [29] and bridge [26] sites on the outmost Pt row in $\mathrm{Pt}(110)$. The situation is different for $\mathrm{Pt}(100)$. A previous study by Skulason et al. [26] found hydrogen to be stable on the bridge site, reaching up to $2 \mathrm{ML}$, two hydrogen atoms per Pt site, on $\operatorname{Pt}(100)$. We also found hydrogen on bridge sites over $\mathrm{Pt}(100)$ as the most stable configuration with a maximum coverage of $2 \mathrm{ML}$. We, therefore, do not discuss further our results for the UPD state of hydrogen on $\operatorname{Pt}(100)$ as they are similar to previous calculations [26].

We start our discussion with the results for the direct MD and MEP of HOR at the $\operatorname{Pt}(100)$ terrace site. We then turn to discuss $E_{a}$ of the HOR on terrace and step sites as a function of electrode potential and end the discussion with the predicted Tafel plot for hydrogen reactions on $\mathrm{Pt}(100)$ terrace sites.

\section{Direct Molecular Dynamics of the HOR}

We first explored the mechanism of the HOR performing molecular dynamics simulations of the reaction of $\mathrm{H}_{2}$ at the terrace sites of the $\operatorname{Pt}(100) /$ water interface. The reaction was studied under three electrochemical conditions: (i) low coverage of adsorbed hydrogen at ca. $0.0 \mathrm{~V}$ vs. RHE, (ii) ca. $1 \mathrm{ML}$ coverage of adsorbed hydrogen at ca. $0.0 \mathrm{~V}$ vs. RHE, and (iii) low coverage of adsorbed hydrogen at ca. $+0.2 \mathrm{~V}$ vs. RHE. A sequence of configurations in the $\mathrm{H}_{2}-\mathrm{Pt}(100)$ surface reaction under the electrochemical conditions $\mathrm{i}$, ii, and iii are shown in Figs. 2, 3, and 4, respectively. These trajectories represent reactive surface processes in which the solvated $\mathrm{H}_{2}$ molecule makes side-on and end-on approaches to the $\operatorname{Pt}(100)$ surface at low and high hydrogen coverage.

The reaction mechanism is straightforward, similar to other water/Pt interfaces [21, 29]. Initially, the $\mathrm{H}_{2}$ molecule is drawn to the metal surface by the attractive interaction with Pt. Subsequently, a rapid bond-breaking process takes place. This process is common around 5 fs to all electrochemical conditions and trajectories (Figs. 2, 3, and 4). Above 5 fs, the dynamics depend on the electrochemical conditions. The dissociation takes place easily because $\mathrm{H}_{2}$ does not need to displace surface water molecules [41]. Near the reversible potential, water molecules are not bound to Pt, as we and other have previously reported (see Ref. [42] and references therein).

At low overpotential and low surface hydrogen coverage (Fig. 2), a highly exothermic non-oxidative adsorption forms two $\mathrm{H}_{\mathrm{b}}$ on the surface. The exothermic energy is imparted to the kinetic energy of one of the $\mathrm{H}_{\mathrm{b}}$ that undergoes a rapid siteto-site shift and to the excitations in the wagging vibrational mode of the other $\mathrm{H}_{\mathrm{b}}(30-55 \mathrm{fs})$. The Tafel process dominates the HOR on $\operatorname{Pt}(100)$ at low overpotential and low hydrogen surface coverage. Under these electrochemical conditions, the majority of trajectories that were examined showed a nonoxidative adsorption of $\mathrm{H}_{2}$ similar to that displayed in (Fig. 2). The oxidation of $\mathrm{H}_{\mathrm{b}}$ at the water/Pt(100) interface will seldom take place because it requires a high $\mathrm{E}_{\mathrm{a}}$ of $6.9 \mathrm{kcal} / \mathrm{mol}$, see discussion in the next section. The Tafel process at low overpotential and low surface hydrogen coverage results in the deposition of hydrogen (i.e., UPD hydrogen) on the $\mathrm{Pt}(100)$ surface.

The HOR via the Heyrovsky-Volmer process begins to take place only when the $\operatorname{Pt}(100)$ surface reaches ca. $1 \mathrm{ML} \mathrm{H}_{\mathrm{b}}$ coverage or when the electrode overpotential is increased. At ca. $1 \mathrm{ML} \mathrm{H}_{\mathrm{b}}$ coverage, where the adsorbed hydrogen tends to block the Tafel process or further deposition of two additional $\mathrm{H}_{\mathrm{b}}$ (Fig. 3), the heterolytic dissociation of $\mathrm{H}_{2}$ takes place to form a proton and $\mathrm{H}_{\mathrm{b}}$ on the femtosecond time scale (10$20 \mathrm{fs}$ ). This was followed by a site-to-site shift of $\mathrm{H}_{\mathrm{b}}$.

$\mathrm{H}_{2}$ follows a similar dissociative oxidation pathway at the intermediate overpotential of ca. $+0.2 \mathrm{~V}$ vs. RHE even at low hydrogen surface coverage (Fig. 4). Thus, the direct dissociative oxidation of $\mathrm{H}_{2}$ via the Heyrovsky-Volmer process is found to be the minimum energy pathway for the HOR at ca. $1 \mathrm{ML} \mathrm{H}_{\mathrm{b}}$ coverage at low overpotential as well as at low hydrogen coverage and higher electrode potentials; results are shown in Fig. 5. In both of these electrochemical conditions, $\mathrm{H}_{2}$ spontaneously dissociates to form a proton and $\mathrm{H}_{\mathrm{b}}$.

Our results can help to rationalize the current density experimentally observed near the reversal potential in the $\operatorname{Pt}(100)$ voltammogram [40]. Under experimental conditions at low overpotential, the $\mathrm{Pt}(100)$ and $\mathrm{Pt}(111)$ surfaces are known $[26,34]$ to be covered with adsorbed hydrogen. According to our molecular dynamics simulations and minimum energy pathway calculations, the HOR on the $\mathrm{Pt}(100)$ surface takes place at Pt sites that are partially covered with nonreactive adsorbed hydrogen. This contrasts with the HOR on the $\operatorname{Pt}(111)$ surface, where the inactive adsorbed hydrogen saturate $[26,28]$ the surface at low overpotential and blocks the active Pt sites. As a result, no current density is observed near the reversible potential in the $\mathrm{Pt}(111)$ voltammogram [40]. 
Fig. 2 A sequence of atomic configurations in a sample MD trajectory of the Tafel step in $\mathrm{H}_{2}$ oxidation on $\mathrm{Pt}(100)$ terraces sites at low coverage (in the absence) of adsorbed hydrogen at ca. $0.0 \mathrm{~V}$ vs. RHE. $\mathrm{H}_{2} / 2 \mathrm{H}_{\mathrm{b}}$ is highlighted in yellow
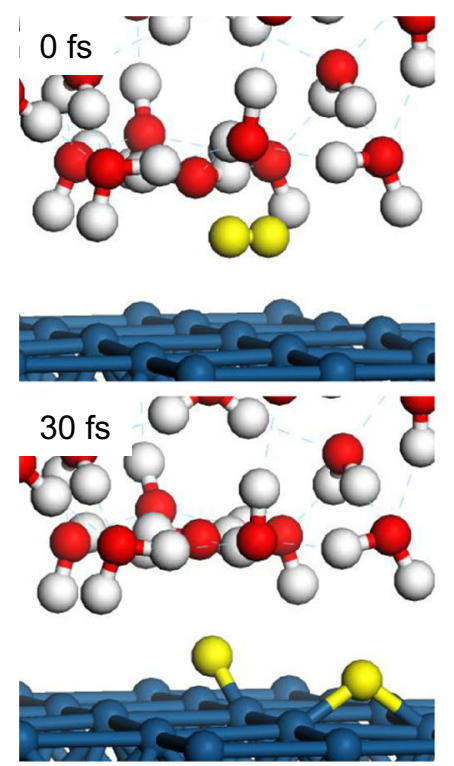
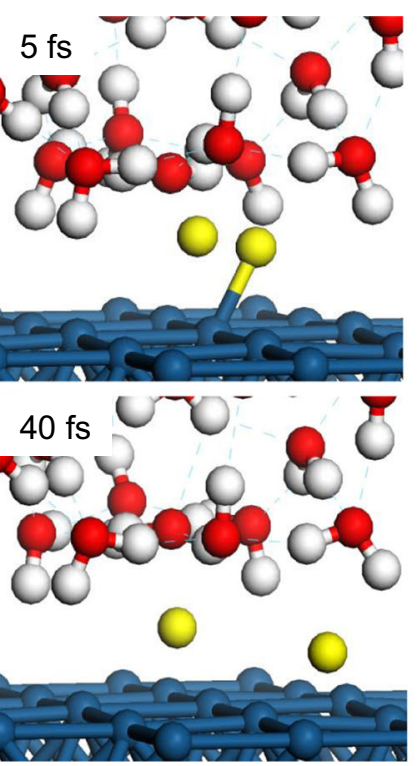
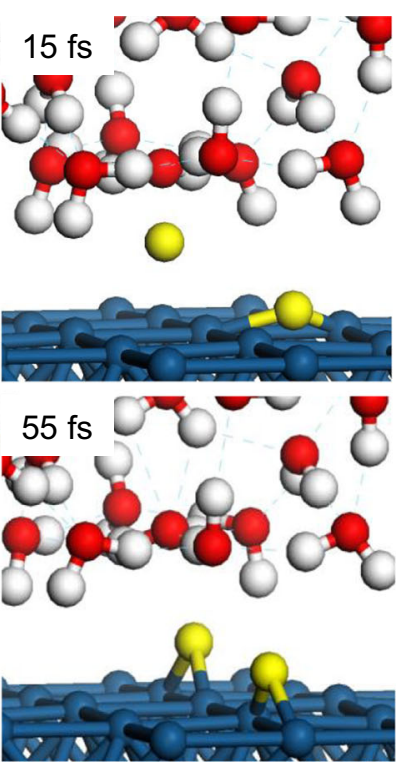

\section{Reversible Electrode Potential}

To better understand the results of our molecular dynamics for the HOR near the reversible potential, we evaluated the $\mathrm{H}_{2} /$ $\mathrm{Pt}(100) /$ water potential energy surface to establish the minimum energy pathway. A relative energy diagram is shown in Fig. 6 for $\mathrm{H}_{2} / \mathrm{Pt}(100) /$ water at low coverage of adsorbed hydrogen at ca. $0.0 \mathrm{~V}$ vs. RHE. As expected, the energy of $1 / 2 \mathrm{H}_{2(\mathrm{~g})}$ is close to that of $\left(\mathrm{H}_{3} \mathrm{O}^{+}+e^{-}\right)$near the reversible potential. In line with the molecular dynamics results at ca. $0.0 \mathrm{~V}$ vs. RHE, the minimum energy pathway calculations show that the $\mathrm{H}_{2}$ dissociation is barrierless and exothermic by $15 \mathrm{kcal} / \mathrm{mol}$. The homolytic $\mathrm{H}-\mathrm{H}$ bond breaking forms two $\mathrm{H}_{\mathrm{b}}$ with an average interatomic Pt-H distance of $1.72 \AA$. The vibrational frequency for the stretching mode of $\mathrm{H}_{b}$ is

Fig. 3 A sequence of atomic configurations in a sample MD trajectory of the HeyrovskyVolmer process in $\mathrm{H}_{2}$ oxidation on $\operatorname{Pt}(100)$ terrace sites at ca. 1 ML coverage of adsorbed hydrogen at ca. $0.0 \mathrm{~V}$ vs. RHE. $\mathrm{H}_{2} / 2 \mathrm{H}$ is highlighted in yellow

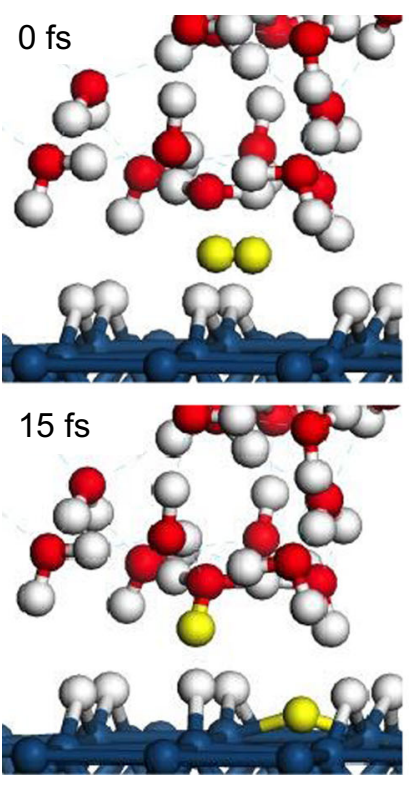

calculated at $1467 \mathrm{~cm}^{-1}$, after correcting for anharmonicity [43]. The energy released upon the dissociation goes into the product internal energy, resulting in the site-to-site shift and vibrational excitation of $\mathrm{H}_{\mathrm{b}}$ observed in the molecular dynamics (Fig. 2). The rapid site-to-site diffusion of $\mathrm{H}$ has been also established for other Pt surfaces [44].

$\mathrm{H}_{\mathrm{b}}$ interacts very little with solution water; the interatomic $\mathrm{H}_{\mathrm{b}}-\left(\mathrm{H}_{2} \mathrm{O}\right)_{\text {sol }}$ distances are over $3 \AA$. The HOR of $\mathrm{H}_{\mathrm{b}}$, therefore, can take place only when $\mathrm{H}_{\mathrm{b}}$ is activated and isomerized to an on-top hydrogen $\mathrm{H}_{\mathrm{o}}$. We found an $\mathrm{E}_{\mathrm{a}}$ of $6.9 \mathrm{kcal} / \mathrm{mol}$ for this isomerization (Fig. 6) on the water $/ \mathrm{Pt}(100)$ interface at low hydrogen coverage. This relatively high $\mathrm{E}_{\mathrm{a}}$ comes in part from the different binding energy of $\mathrm{H}_{\mathrm{b}}(68 \mathrm{kcal} / \mathrm{mol})$ and $\mathrm{H}_{\mathrm{o}}$ $(63 \mathrm{kcal} / \mathrm{mol})$ and helps to explain the absence of an oxidative pathway at low coverage of adsorbed hydrogen at ca. $0.0 \mathrm{~V}$ vs.
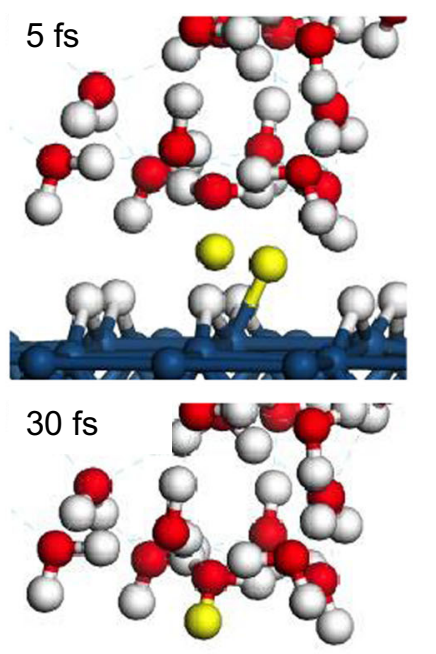

hinhon
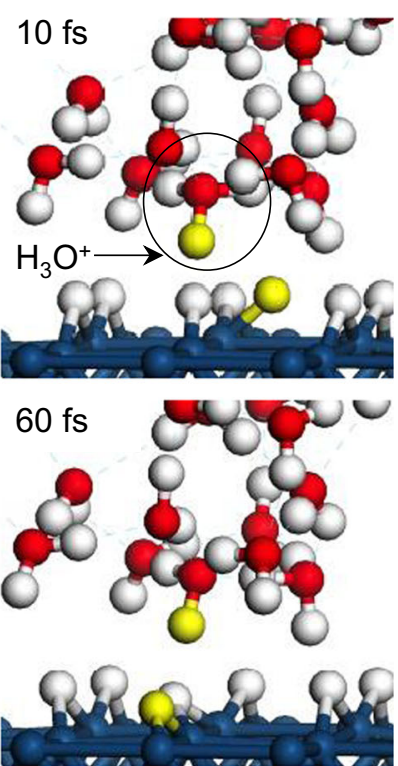
Fig. 4 A sequence of atomic configurations in a sample MD trajectory of the HeyrovskyVolmer process in $\mathrm{H}_{2}$ oxidation on $\operatorname{Pt}(100)$ terrace sites at low coverage of adsorbed hydrogen at ca. $+0.2 \mathrm{~V}$ vs. RHE. $\mathrm{H}_{2} / 2 \mathrm{H}$ is highlighted in yellow
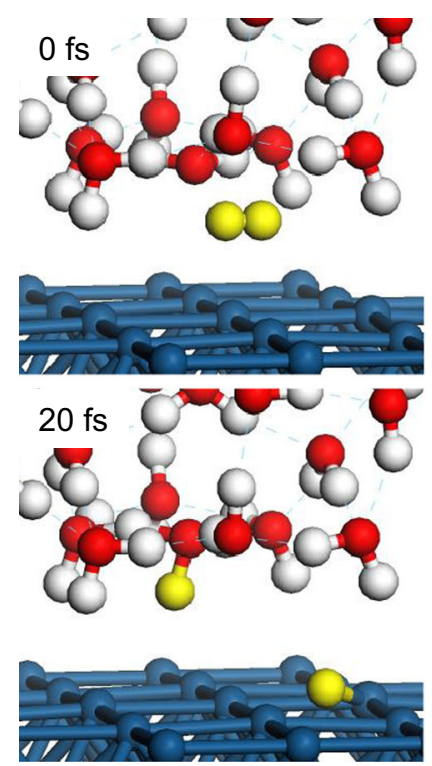
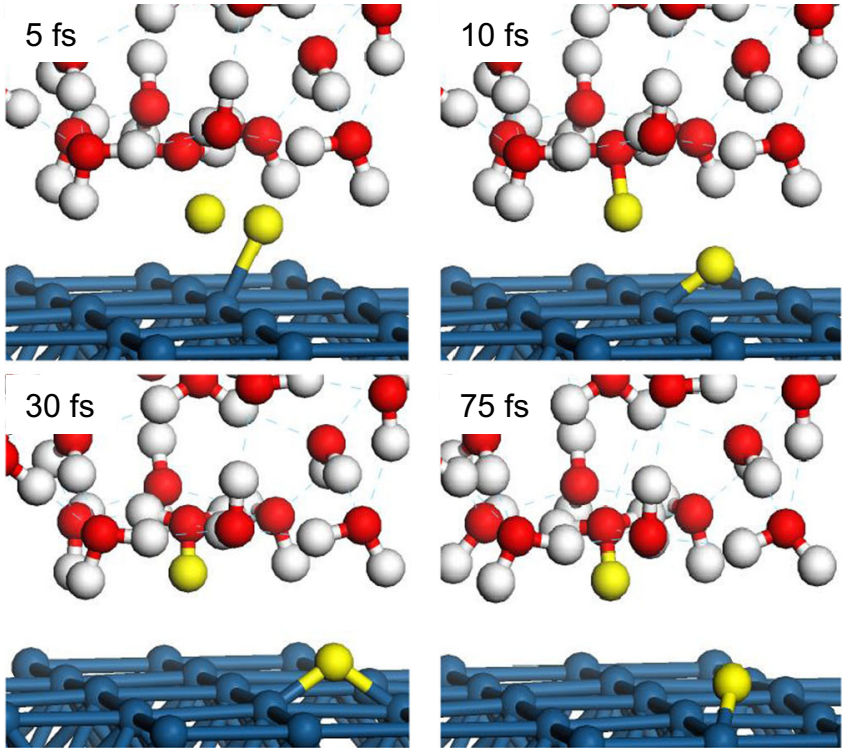

RHE within the time frame of our direct molecular dynamics simulations. Once $\mathrm{H}$ is in an on-top position $\left(\mathrm{H}_{\mathrm{o}}\right.$; Fig. 6), a hydrogen bond with an interatomic $\mathrm{H}_{\mathrm{o}}-\left(\mathrm{OH}_{2}\right)_{\text {sol }}$ distance of ca. $1.73 \AA$ is formed. The vibrational frequency for the stretching mode of $\mathrm{H}_{\mathrm{o}}$ is $2023 \mathrm{~cm}^{-1}$. The direct interaction of $\mathrm{H}_{\mathrm{o}}$ with solution water allows the oxidation of $\mathrm{H}_{\mathrm{o}}$ via the Volmer process. The oxidation, however, is not spontaneous; $\mathrm{E}_{\mathrm{a}}$ is $1.7 \mathrm{kcal} / \mathrm{mol}$ (Fig. 6).
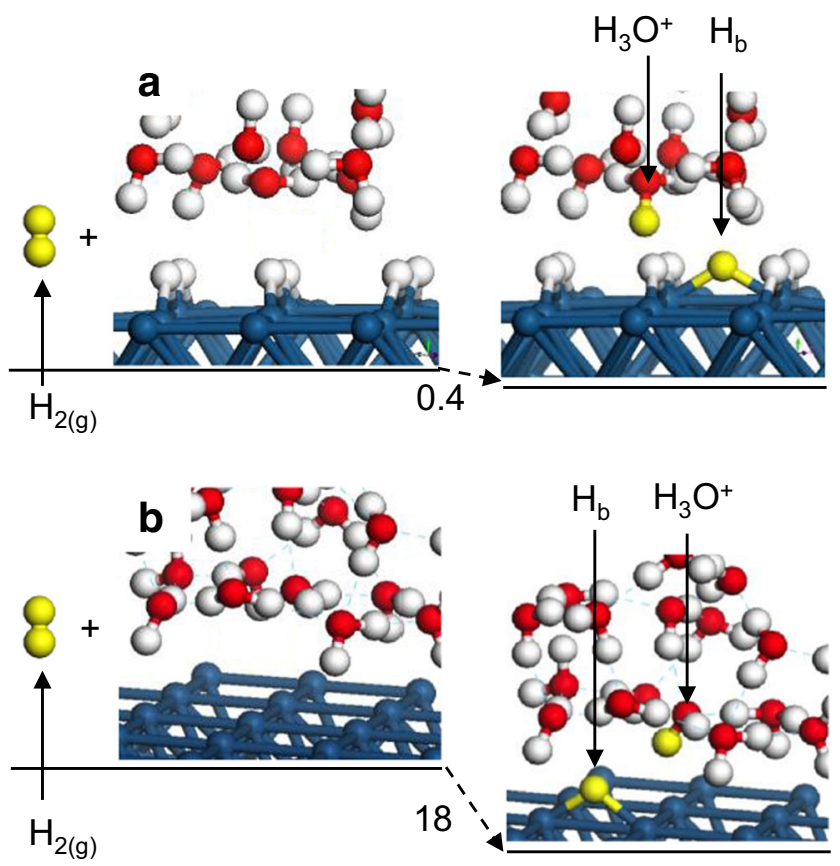

Fig. 5 Relative energy diagram of the Heyrovsky-Volmer pathway of the $\mathrm{H}_{2}$ oxidation at a ca. $1 \mathrm{ML}$ coverage of adsorbed hydrogen at ca. $0.0 \mathrm{~V}$ vs. RHE and $\mathbf{b}$ low coverage of adsorbed hydrogen at ca. $+0.2 \mathrm{~V}$ vs. RHE on $\mathrm{Pt}(100)$ terrace sites. $\mathrm{H}_{2} / 2 \mathrm{H}$ is highlighted in yellow. The reaction energy is given in $\mathrm{kcal} / \mathrm{mol}$
As shown in Figs. 7a and 8, $\mathrm{E}_{\mathrm{a}}$ for the $\mathrm{H}_{\mathrm{o}} \rightarrow \mathrm{H}_{3} \mathrm{O}^{+}+e^{-}$ Volmer oxidation step and the $\mathrm{H}_{\mathrm{b}} \rightarrow \mathrm{H}_{\mathrm{o}}$ isomerization step on $\mathrm{Pt}(100)$ terrace sites, respectively, depend on the electrode potential. The potential where $\mathrm{E}_{\mathrm{a}}$ for the forward $\left(\mathrm{H}_{\mathrm{o}} \rightarrow\right.$ $\left.\mathrm{H}_{3} \mathrm{O}^{+}+e^{-}\right)$and reverse $\left(\mathrm{H}_{3} \mathrm{O}^{+}+e^{-} \rightarrow \mathrm{H}_{\mathrm{o}}\right)$ reactions are equal (the crossing point in Fig. $7 \mathrm{a}$ ) is achieved at $q \sim-2$. This $\mathrm{E}_{\mathrm{a}}$ and the crossing potential are rather insensitive to the surface hydrogen coverage. At the crossing potential, $\mathrm{E}_{\mathrm{a}}$ is close to $1.7 \mathrm{kcal} / \mathrm{mol}$ at low and ca. $1 \mathrm{ML}$ hydrogen coverage. The value of $1.7 \mathrm{kcal} / \mathrm{mol}$ was determined by interpolation. As mentioned in Computational Details, this crossing potential corresponds to the reversible potential (i.e., $0.0 \mathrm{~V}$ vs. RHE) when gaseous $1 / 2 \mathrm{H}_{2}$ is in equilibrium with $\left(\mathrm{H}_{3} \mathrm{O}^{+}+e^{-}\right)$. As shown in (Fig. 5a), gaseous $1 / 2 \mathrm{H}_{2}$ is in equilibrium with $\left(\mathrm{H}_{3} \mathrm{O}^{+}+e^{-}\right)$when the hydrogen coverage is ca. $1 \mathrm{ML}$. At low coverage, however, the gaseous $1 / 2 \mathrm{H}_{2}$ state is not in equilibrium with the $\left(\mathrm{H}_{3} \mathrm{O}^{+}+e^{-}\right)$state (Fig. 6).

$\mathrm{E}_{\mathrm{a}}$ for the isomerization at terrace sites on $\mathrm{Pt}(100)$ near $0.0 \mathrm{~V}$ vs. RHE are 6.9 and $5.6 \mathrm{kcal} / \mathrm{mol}$ at low and ca. $1 \mathrm{ML}$ hydrogen coverage, respectively. As the overpotential is increased, i.e., added positive charge, $\mathrm{E}_{\mathrm{a}}$ for the oxidation step decreases, vanishing at $q=-1$ (ca. $+0.1 \mathrm{~V}$ vs. RHE) for hydrogen coverage of ca. 1 ML. Similarly, $\mathrm{E}_{\mathrm{a}}$ for the $\mathrm{H}_{\mathrm{b}} \rightarrow \mathrm{H}_{\mathrm{o}}$ isomerization decreases with increasing overpotential, but it does not vanish and instead reaches a value of ca. $2.7 \mathrm{kcal} / \mathrm{mol}$ at potentials of ca. $+0.4 \mathrm{~V}$ vs. RHE and hydrogen coverage of ca. 1 ML (Fig. 8).

The HOR does not only take place at terrace sites but also at steps sites on the $\mathrm{Pt}(100)$ surface [6]. We, therefore, evaluated the minimum energy pathway of HOR at the (111) step site of $\mathrm{Pt}(100)$ as well. A relative energy diagram is shown in Fig. 9 for $\mathrm{H}_{2} /$ water/stepped $\mathrm{Pt}(100)$ at low coverage of adsorbed hydrogen at ca. $0.0 \mathrm{~V}$ vs. RHE. Hydrogen dissociation at the step sites follows an exothermic non-oxidative 
Fig. 6 Relative energy diagram of the Tafel-Volmer pathway of the $\mathrm{H}_{2}$ oxidation at low coverage of adsorbed hydrogen at ca. $0.0 \mathrm{~V}$ vs. RHE on Pt(100) terrace sites. $\mathrm{H}_{2} / 2 \mathrm{H}$ is highlighted in yellow. Reaction and activation energies are given in $\mathrm{kcal} / \mathrm{mol}$

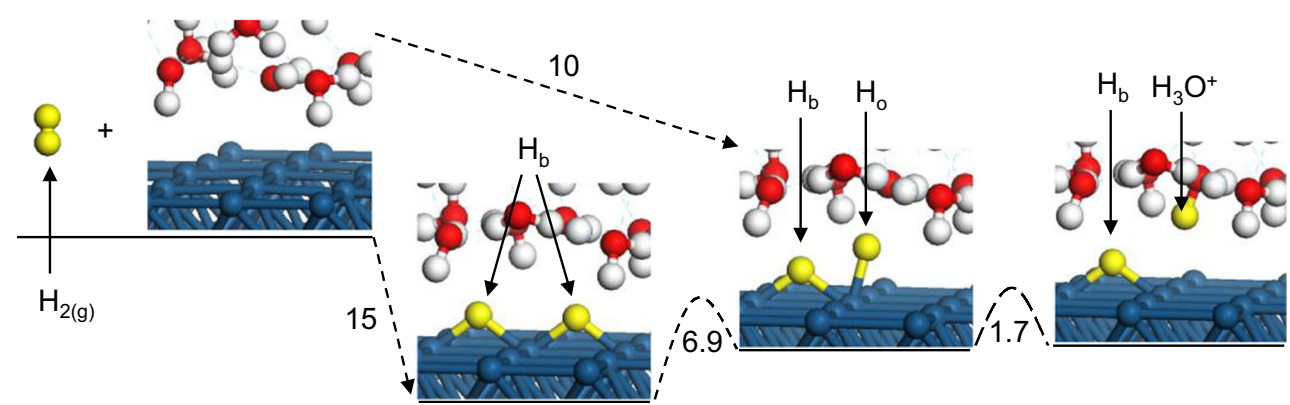

adsorption forming two $\mathrm{H}_{\mathrm{b}}$ on the outmost step Pt atoms. $\mathrm{H}_{\mathrm{b}}$ on the step site has an asymmetry structure with interatomic $\mathrm{Pt}-\mathrm{H}_{\mathrm{b}}$ distances of 1.66 and $1.78 \AA$. The vibrational frequency for the stretching mode of $\mathrm{H}_{\mathrm{b}}$ ranges from 1601 to $1829 \mathrm{~cm}^{-1}$. Similar to the $\mathrm{H}_{\mathrm{b}}$ on terrace sites, the interatomic $\mathrm{H}_{\mathrm{b}}-\left(\mathrm{H}_{2} \mathrm{O}\right)_{\mathrm{sol}}$
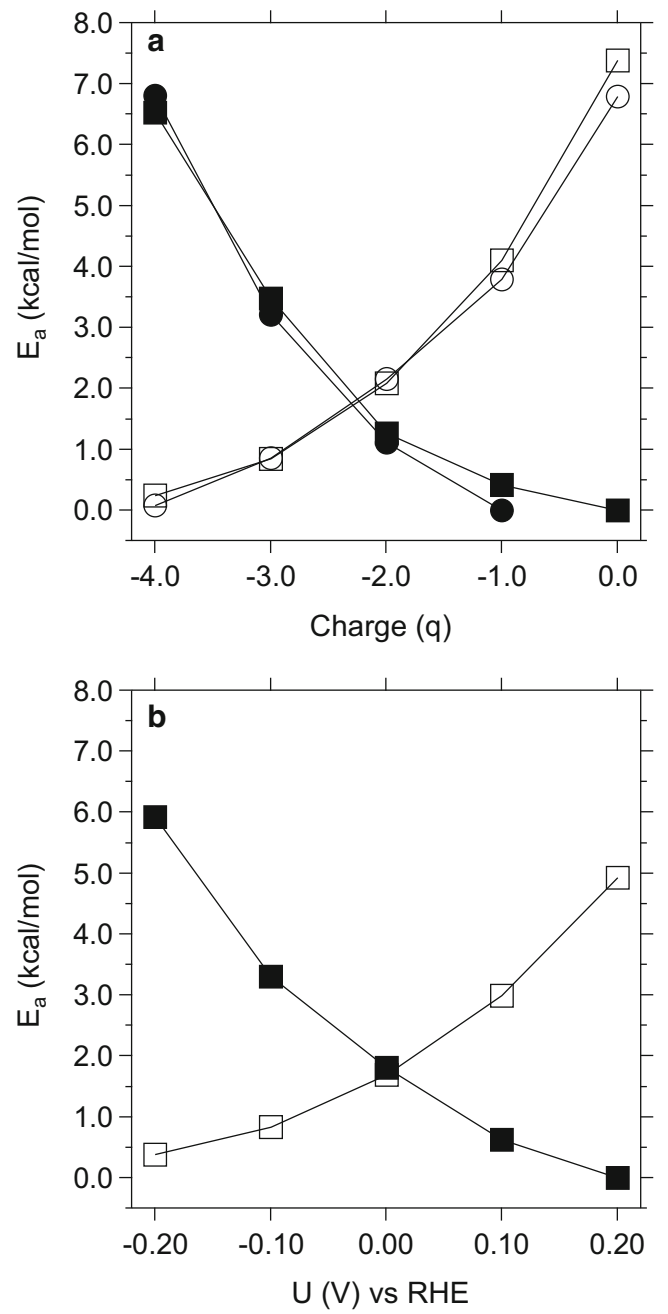

Fig. 7 Activation energy $\left(\mathrm{E}_{\mathrm{a}}\right)$ for the Volmer step in the hydrogen oxidation $\left(\mathrm{H}_{\mathrm{o}} \rightarrow \mathrm{H}_{3} \mathrm{O}^{+}+e^{-}\right.$, closed symbols $)$and hydrogen evolution $\left(\mathrm{H}_{3} \mathrm{O}^{+}+e^{-} \rightarrow \mathrm{H}_{\mathrm{o}}\right.$, open symbols $)$ reactions as a function of the electrode potential (or added Charge $q$ ) at the water/ $\operatorname{Pt}(100)$ interface. Results are shown for a Pt $(100)$ terrace sites at low (square symbols) and ca. $1 \mathrm{ML}$ (circle symbols) coverage of adsorbed hydrogen and for $\mathbf{b} \mathrm{Pt}(100)$ with (111) step sites at low coverage of adsorbed hydrogen distances are over $3 \AA$ for $\mathrm{H}_{\mathrm{b}}$ on the step site. $\mathrm{H}_{\mathrm{b}}$ on the step site, therefore, does not interact strongly with solution water.

The oxidation of $\mathrm{H}_{2}$ on step sites at low coverage of adsorbed hydrogen at $0.0 \mathrm{~V}$ vs. RHE also requires the activation and isomerization of adsorbed hydrogen from the bridge to the on-top site. $\mathrm{E}_{\mathrm{a}}$ for the $\mathrm{H}_{\mathrm{b}}$ to $\mathrm{H}_{\mathrm{o}}$ isomerization is insensitive to the electro potential (Fig. 8) in the case of step sites, with a value of ca. $4.5 \mathrm{kcal} / \mathrm{mol}$. $\mathrm{H}_{\mathrm{o}}$ on the step site has a Pt- $\mathrm{H}_{\mathrm{o}}$ distance of $1.55 \AA$ and a vibrational frequency for the stretching mode of $1991 \mathrm{~cm}^{-1}$. $\mathrm{H}_{\mathrm{o}}$ on the step site also forms a hydrogen bond with solution water; with a distance of $1.83 \AA$. Similar to the HOR on terrace sites, the $\mathrm{H}_{0} \rightarrow$ $\mathrm{H}_{3} \mathrm{O}^{+}+e^{-}$Volmer mechanism on step sites depends on the electrode potential (Fig. $7 b$ ). $E_{a}$ at the reversible potential is coincidentally also $1.7 \mathrm{kcal} / \mathrm{mol}$.

The calculated $\mathrm{E}_{\mathrm{a}}$ for the oxidation of UPD hydrogen, $\mathrm{H}_{\mathrm{b}} \rightarrow \mathrm{H}_{\mathrm{o}} \rightarrow \mathrm{H}_{3} \mathrm{O}^{+}+e^{-}$, at the reversible potential on $\mathrm{Pt}(100)$ at terrace and step sites, 6.9 and $4.5 \mathrm{kcal} / \mathrm{mol}$, respectively, are much higher than the measured [6] value of $2.87 \mathrm{kcal} /$ mol. This is in contrast with the oxidation of UPD hydrogen

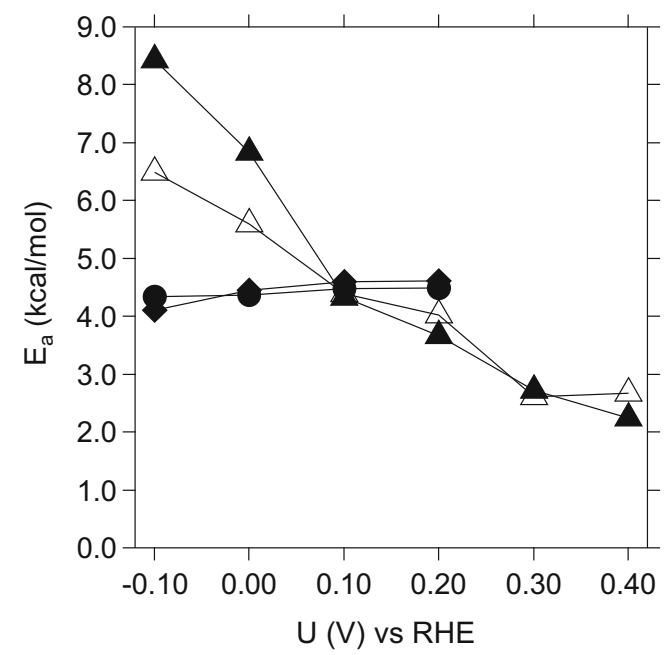

Fig. 8 Activation energy $\left(E_{a}\right)$ for the isomerization of bridging hydrogen, $\mathrm{H}_{\mathrm{b}}$, to on-top hydrogen, $\mathrm{H}_{\mathrm{o}},\left(\mathrm{H}_{\mathrm{b}} \rightarrow \mathrm{H}_{\mathrm{o}}\right)$ as functions of the electrode potential at the $\mathrm{Pt}(100)$ terrace (triangle symbols) and (111) step (circle symbols) sites. Results for the isomerization of $\mathrm{H}_{\mathrm{b}}$ at $\mathrm{Pt}(111)$ terrace sites are also included (diamond symbols) for comparison. For the isomerization at the $\operatorname{Pt}(100)$ terrace sites, results are shown for low (closed triangle symbols) and ca. $1 \mathrm{ML}$ (open triangle symbols) coverage of adsorbed hydrogen 
Fig. 9 Relative energy diagram of the Heyrovsky-Volmer pathway of the $\mathrm{H}_{2}$ oxidation at low coverage of adsorbed hydrogen at ca. $0.0 \mathrm{~V}$ vs. RHE on $\operatorname{Pt}(100)$ with (111) step sites. Reaction and activation energies are given in $\mathrm{kcal} / \mathrm{mol}$

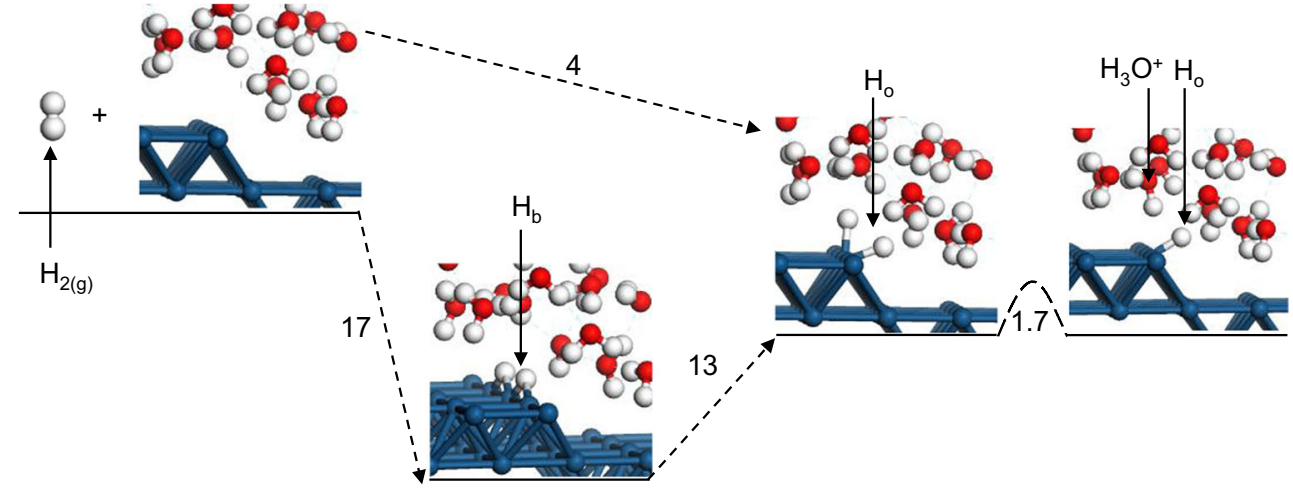

on $\operatorname{Pt}(111)$ and $\operatorname{Pt}(110)$. To compare with $\operatorname{Pt}(100)$, we also studied the $\mathrm{H}_{\mathrm{b}} \rightarrow \mathrm{H}_{\mathrm{o}}$ isomerization on $\mathrm{Pt}(111)$; results are included in (Fig. 8). The calculated $\mathrm{E}_{\mathrm{a}}$ for the oxidation of UPD hydrogen on $\mathrm{Pt}(111)$ is ca. $4.5 \mathrm{kcal} / \mathrm{mol}$, which is rather insensitive to the electrode potential. This value agrees with the measured [6] value of $4.3 \mathrm{kcal} / \mathrm{mol}$. $\mathrm{E}_{\mathrm{a}}$ for the oxidation of UPD hydrogen on $\mathrm{Pt}(110)$ is $2.3 \mathrm{kcal} / \mathrm{mol}$ [29], in agreement with the measured [6] value of $2.27 \mathrm{kcal} / \mathrm{mol}$. It is likely that $\mathrm{E}_{\mathrm{a}}, 2.87 \mathrm{kcal} / \mathrm{mol}$ [6], determined experimentally is not for the oxidation of UPD hydrogen, $\mathrm{H}_{\mathrm{b}}$, but for the oxidation of $\mathrm{H}_{\mathrm{o}}$ generated in the Heyrovsky-Volmer process.

Our results show that the oxidation of UPD hydrogen on $\operatorname{Pt}(111)$ and $\operatorname{Pt}(100)$ differ from that on $\operatorname{Pt}(110)$. On $\operatorname{Pt}(110)$, where hydrogen is stable only at on-top position [29], the oxidation of UPD hydrogen taking place via the $\mathrm{H}_{\mathrm{o}} \rightarrow$ $\mathrm{H}_{3} \mathrm{O}^{+}+e^{-}$Volmer mechanism with a low $\mathrm{E}_{\mathrm{a}}$. The low $\mathrm{E}_{\mathrm{a}}$ result in a high HOR activity in this surface, as indicated by the high current density in the $\operatorname{Pt}(110)$ voltammogram [29]. On the other hand, UPD hydrogen is at bridge position on $\operatorname{Pt}(111)$ and $\mathrm{Pt}(100)$. The oxidation of UPD hydrogen on these surfaces proceeds via the $\mathrm{H}_{\mathrm{b}} \rightarrow \mathrm{H}_{\mathrm{o}} \rightarrow \mathrm{H}_{3} \mathrm{O}^{+}+e^{-}$mechanism. As shown above, the $\mathrm{H}_{b} \rightarrow \mathrm{H}_{\mathrm{o}}$ isomerization step requires relatively high $\mathrm{E}_{\mathrm{a}}$, resulting in the low current density observed in the UPD region in the voltammogram of these surfaces [29]. The current density is particularly low for $\operatorname{Pt}(100)$ where $\mathrm{E}_{\mathrm{a}}$ for the $\mathrm{H}_{\mathrm{b}} \rightarrow \mathrm{H}_{\mathrm{o}}$ isomerization is relatively high.

\section{Tafel Plot}

As in our previous work [29], here we employed the calculated electrode potential-dependent $\mathrm{E}_{\mathrm{a}}$ for $\mathrm{H}_{2}$ oxidation on $\mathrm{Pt}(100)$ to predict the Tafel plot in the spirit of Anderson and Cai [16]. In the low overpotential region, where oxidation and reduction reactions would contribute nearly equally [16], the total current density $i$ may be given by $i=i_{\mathrm{ox}}+i_{\text {red }}=\mathrm{A}$ $\left(\exp \left[\mathrm{E}_{\mathrm{a}}{ }^{\mathrm{ox}}(\mathrm{U}) / \mathrm{RT}\right]+\exp \left[\mathrm{E}_{\mathrm{a}}{ }^{\text {red }}(\mathrm{U}) / \mathrm{RT}\right]\right)$, where $i_{\mathrm{ox}}$ and $i_{\text {red }}$ are, respectively, oxidation and reduction kinetic current density. The pre-exponential factor $\mathrm{A}$ is proportional to a number of variables, such as the concentration of adsorbed hydrogen/ proton undergoing oxidation/reduction, the frequency factor, and the Faraday constant. $\mathrm{T}$ is the temperature of the system. $E_{a}(U)$ is the activation energy at a potential $U$ for oxidation or reduction.

$\mathrm{E}_{\mathrm{a}}$ for the Volmer step in the $\mathrm{H}_{\mathrm{o}} \rightarrow \mathrm{H}_{3} \mathrm{O}^{+}+e^{-}$oxidation and $\mathrm{H}_{3} \mathrm{O}^{+}+e^{-} \rightarrow \mathrm{H}_{\mathrm{o}}$ reduction reactions at ca. $1 \mathrm{ML}$ coverage of surface hydrogen on $\mathrm{Pt}(100)$ (Fig. 7a) were fitted to third order polynomial equations and employed to predict the Tafel plot. The predicted Tafel plot is shown in Fig. 10 along with the experimental Tafel plot at $274 \mathrm{~K}$ [6]. The experimental plot is reproduced with the pre-exponential factor $A=16$. We fitted the curve with slopes of 51 and $110 \mathrm{mV} /$ decade. Extrapolation of the $51 \mathrm{mV} /$ decade slope results in an exchange current density $i_{0}=0.37 \mathrm{~mA} \mathrm{~cm}{ }^{-2}$, in agreement with the measured [6] value of $0.36 \mathrm{~mA} \mathrm{~cm}^{-2}$. The calculated slope of $110 \mathrm{mV} /$ decade also agrees with the measured value of $112 \mathrm{mV} /$ decade (Fig. 4 in Ref. [6]). The other calculated slope $(51 \mathrm{mV} / \mathrm{de}-$ cade), however, deviates from the value of $37 \mathrm{mV} /$ decade reported in Ref. [6]. Graphically analyzing the Tafel slopes shown in Fig. 4 of Ref. [6] for Pt(100), we found that the numerical value reported, $37 \mathrm{mV} /$ decade, is not the slope of

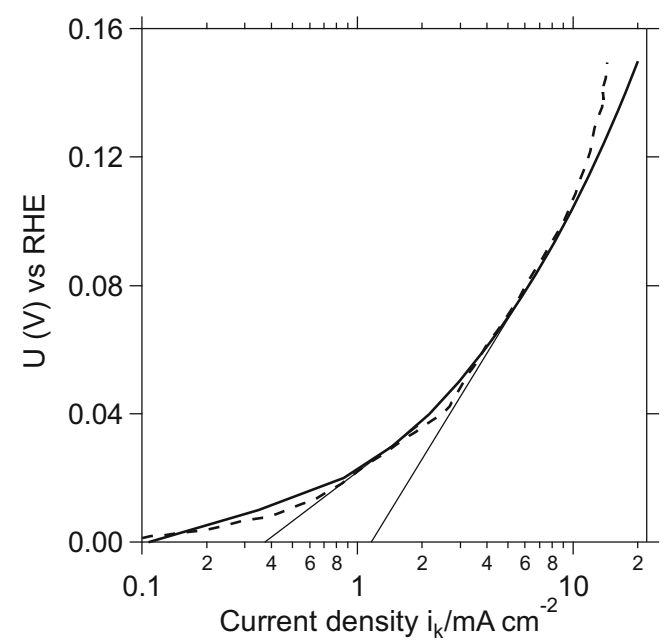

Fig. 10 Tafel plot for hydrogen oxidation at $\mathrm{Pt}(100)$ terrace site at $274 \mathrm{~K}$. The dashed curve corresponds to experimental results of Ref. [6] and the full curve to our prediction employing the activation energy of the hydrogen oxidation/reduction at ca. 1 ML coverage of adsorbed hydrogen (Fig. 7a). The curve was fitted with two Tafel slopes 
the line shown in the figure. The slope in the figure is instead $46 \mathrm{mV} /$ decade, in closer agreement with our calculated value. No differences were found for the slope of $112 \mathrm{mV} /$ decade. The agreement of the calculated and measured Tafel slopes and exchange current density $i_{0}$ for hydrogen reactions on $\operatorname{Pt}(100)$ strongly supports that the electro-oxidation takes place via the Heyrovsky-Volmer mechanism [16].

\section{Conclusions}

In the present work, we have employed the first-principlesbased molecular dynamics to bring atomic-level insight into the hydrogen electro-oxidation at the $\mathrm{Pt}(100) /$ water interface. We studied the effect of inactive adsorbed hydrogen and electrode potential on the electro-oxidation reaction studying the oxidation at low coverage of adsorbed hydrogen at (i) ca. $0.0 \mathrm{~V}$ vs. RHE and (ii) ca. $+0.2 \mathrm{~V}$ vs. RHE, and (iii) at ca. $1 \mathrm{ML}$ coverage of adsorbed hydrogen at ca. $0.0 \mathrm{~V}$ vs. RHE. At ca. $0.0 \mathrm{~V}$ vs. RHE, the electro-oxidation follows the Tafel-Volmer homolytic cleavage of $\mathrm{H}_{2}$ if the coverage of adsorbed hydrogen is low, and the Heyrovsky-Volmer mechanism if the surface is covered with ca. $1 \mathrm{ML}$ of hydrogen. At potential of ca. $+0.2 \mathrm{~V}$ vs. RHE, the oxidation proceeds via the Heyrovsky-Volmer mechanism independently of the surface hydrogen coverage. Good agreement between measured and predicted Tafel plots also indicates that hydrogen oxidation/reduction reaction on $\mathrm{Pt}(100)$ proceeds via the Heyrovsky-Volmer mechanism under ca. 1 ML coverage of inactive adsorbed hydrogen.

We have also studied the oxidation of UPD H on Pt(100). In agreement with previous calculations by Skulason et al. [26], we identified UPD $\mathrm{H}$ as hydrogen in the bridging position on $\operatorname{Pt}(100)$. The electro-oxidation of UPD $\mathrm{H}$ at terrace sites on $\mathrm{Pt}(100)$ requires the isomerization of hydrogen from bridge to on-top position. This surface transformation has a high activation energy, and it is likely to be the ratedetermining step in the electro-oxidation of UPD $\mathrm{H}$ on the $\mathrm{Pt}(100)$ and $\mathrm{Pt}(111)$ surfaces.

Acknowledgments This work was supported by the NASA-UPR Center for Advanced Nanoscale Materials.

Author Contributions The manuscript was written through contributions of all authors. All authors have given approval to the final version of the manuscript.

\section{References}

1. G. Jerkiewicz, Electrocatalysis 1(4), 179-199 (2010)

2. A. Wieckowski, J.K. Nørskov, A. Wieckowski (eds.), Fuel Cell Science: theory, fundamentals, and biocatalysis, Seriesth edn. (John Wiley \& Sons, Inc, New Jersey, 2010)
3. R.J. Nichols, A. Bewick, J. Electroanal. Chem. Interfacial. Electrochem. 243(2), 445-453 (1988)

4. R. Gomez, A. Fernandez-Vega, J.M. Feliu, A.J. Aldaz, Phys. Chem. 97(18), 4769-4776 (1993)

5. N.M. Markovića, S.T. Sarraf, H.A. Gasteiger, P.N. Ross, J. Chem. Soc. Faraday Trans. 92(20), 3719-3725 (1996)

6. N.M. Marković, B.N. Grgur, P.N. Ross, J. Phys. Chem. B 101(27), 5405-5413 (1997)

7. A. Peremans, A.J. Tadjeddine, Chem. Phys. 103(16), 7197-7203 (1995)

8. B. Ren, X. Xu, X.Q. Li, W.B. Cai, Z.Q. Tian, Surf. Sci. 427, 157161 (1999)

9. N. Nanbu, T.J. Ohsaka, Electroanal. Chem. 485(2), 128-134 (2000)

10. K. Kunimatsu, T. Senzaki, G. Samjeské, M. Tsushima, M. Osawa, Electrochim. Acta 52(18), 5715-5724 (2007)

11. H. Ogasawara, M. Ito, Chem. Phys. Lett. 221(3-4), 213-218 (1994)

12. M. Nakamura, T. Kobayashi, N. Hoshi, Surf. Sci. 605(15-16), 1462-1465 (2011)

13. E. Santos, W. Schmickler, in Catalysis in Electrochemistry, ed. by E. Santos, W. Schmickler (John Wiley \& Sons, Inc, Hoboken, 2011), pp. 197-222

14. A. Gross, S. Schnur, in Catalysis in Electrochemistry, ed. by E. Santos, W. Schmickler (John Wiley \& Sons, Inc, Hoboken, 2011), pp. 165-196

15. P. Ferrin, M. Mavrikakis, J. Rossmeisl, J.K. Nørskov, in Fuel cell science, ed. by A. Wieckowski, J.K. Nørskov (John Wiley \& Sons, Inc, Hoboken, 2010), pp. 489-510

16. A.B. Anderson, Y. Cai, J. Phys. Chem. B 108(52), 19917-19920 (2004)

17. J. Greeley, J.K. Nørskov, L.A. Kibler, A.M. El-Aziz, D.M. Kolb, ChemPhysChem 7(5), 1032-1035 (2006)

18. C. Taylor, S. Wasileski, J.-S. Filhol, M. Neurock, Phys. Rev. B 73(16), $165402(2006)$

19. O. Sugino, I. Hamada, M. Otani, Y. Morikawa, T. Ikeshoji, Y. Okamoto, Surf. Sci. 601(22), 5237-5240 (2007)

20. E. Skúlason, G.S. Karlberg, J. Rossmeisl, T. Bligaard, J. Greeley, H. Jónsson, J.K. Nørskov, Phys. Chem. Chem. Phys. 9(25), 3241 (2007)

21. Y. Ishikawa, J.J. Mateo, D.A. Tryk, C.R.J. Cabrera, Electroanal. Chem. 607(1-2), 37-46 (2007)

22. J. Rossmeisl, E. Skúlason, M.E. Björketun, V. Tripkovic, J.K. Nørskov, Chem. Phys. Lett. 466(1-3), 68-71 (2008)

23. E. Santos, A. Lundin, K. Pötting, P. Quaino, W.J. Schmickler, Solid State Electrochem. 13(7), 1101-1109 (2008)

24. I. Hamada, Y. Morikawa, J. Phys. Chem. C 112(29), 10889-10898 (2008)

25. R. Jinnouchi, A.B. Anderson, J. Phys. Chem. C 112(24), 87478750 (2008)

26. E. Skúlason, V. Tripkovic, M.E. Björketun, S. Gudmundsdóttir, G. Karlberg, J. Rossmeisl, T. Bligaard, H. Jónsson, J.K. Nørskov, J. Phys. Chem. C 114(42), 18182-18197 (2010)

27. J. Rossmeisl, K. Chan, R. Ahmed, V. Tripković, M.E. Björketun, Phys. Chem. Chem. Phys. 15(25), 10321 (2013)

28. J.J. Mateo, D.A. Tryk, C.R. Cabrera, Y. Ishikawa, Mol. Simul. 34(10-15), 1065-1072 (2008)

29. J.A. Santana, J.J. Mateo, Y. Ishikawa, J. Phys. Chem. C 114(11), 4995-5002 (2010)

30. B. Delley, J. Chem. Phys. 113(18), 7756-7764 (2000)

31. J.P. Perdew, K. Burke, M. Ernzerhof, Phys. Rev. Lett. 77(18), 3865-3868 (1996)

32. K. Christmann, in Electrocatalysis, ed. by J. Lipkowski, P.N. Ross (Wiley-VCH, New York, 1998), p. 1

33. R. Gómez, J.M. Orts, B. Álvarez-Ruiz, J.M. Feliu, J. Phys. Chem. B 108(1), 228-238 (2004)

34. N. Garcia-Araez, J. Phys. Chem. C 115(2), 501-510 (2011) 
35. A. Zolfaghari, M. Chayer, G.J. Jerkiewicz, Electrochem. Soc. 144(9), 3034-3041 (1997)

36. S. Trasatti, Pure Appl. Chem. 58(7), 955-966 (1986)

37. C. Venkataraman, A.V. Soudackov, S. Hammes-Schiffer, J. Phys. Chem. C 112(32), 12386-12397 (2008)

38. D. Marx, M.E. Tuckerman, J. Hutter, M. Parrinello, Nature 397(6720), 601-604 (1999)

39. D.S. Strmcnik, P. Rebec, M. Gaberscek, D. Tripkovic, V. Stamenkovic, C. Lucas, N.M. Marković, J. Phys. Chem. C 111(50), 18672-18678 (2007)
40. D. Strmenik, D. Tripkovic, D. van der Vliet, V. Stamenkovic, N.M. Marković, Electrochem. Commun. 10(10), 1602-1605 (2008)

41. G. Jerkiewicz, G. Vatankhah, S. Tanaka, J. Lessard, Langmuir 27(7), 4220-4226 (2011)

42. J.A. Santana, Y. Ishikawa, Electrochim. Acta 56(2), 945-952 (2010)

43. J.P. Merrick, D. Moran, L. Radom, J. Phys. Chem. A 111(45), 11683-11700 (2007)

44. G.W. Watson, R.P.K. Wells, D.J. Willock, G.J. Hutchings, J. Phys. Chem. B 105(21), 4889-4894 (2001) 